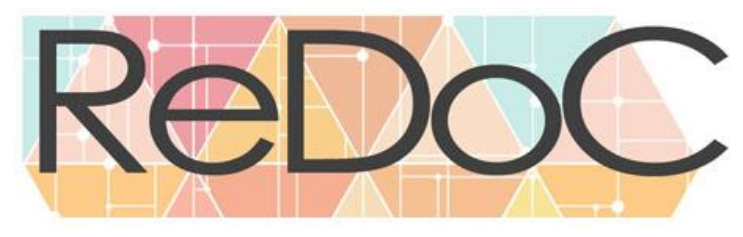

Revista Docência e Cibercultura

\title{
APRENDIZAGEM COLABORATIVA E CARTOGRAFIA COGNITIVA: FORMAÇÃO DE PROFESSORES DO PROGRAMA AGRINHO COM BASE NO PENSAMENTO COMPLEXO
}

COLLABORATIVE LEARNING AND COGNITIVE CARTOGRAPHY: TEACHERS TRAINING OF THE AGRINHO PROGRAM BASED ON COMPLEX THINKING

\section{APRENDIZAJE COLABORATIVO Y CARTOGRAFÍA COGNITIVA:} FORMACIÓN DE PROFESORES DEL PROGRAMA AGRINHO CON BASE EN EL PENSAMIENTO COMPLEJO

\author{
Patrícia Lupion Torres ${ }^{1}$ \\ Jéssica Karollayne Pinheiro Lopes ${ }^{2}$ \\ Rafael Augusto Camargo ${ }^{3}$
}

\section{RESUMO}

Desde 2012, o Programa Agrinho, concebido em 1995, oferta cursos na modalidade de educação a distância (EAD) a professores a fim de incentivá-los à pesquisa e prepará-los para temas de relevância social da contemporaneidade por meio de uma proposta pedagógica baseada no pensamento complexo. Por conseguinte, esta pesquisa tem o objetivo de analisar como os princípios do pensamento complexo se fazem presentes nos cursos de formação permanente ofertados pelo Programa Agrinho, na modalidade de EAD, a professores tanto da rede pública como privada. Este trabalho classifica-se como um estudo de caso descritivo com abordagem qualitativa, uma vez que os dados foram coletados a partir de experiências obtidas por intermédio de diferentes cursos fornecidos pelo referido programa. Conclui-se que as estratégias pedagógicas de Aprendizagem Colaborativa e de Cartografia Cognitiva adotadas nos cursos contribuíram para fornecer aos participantes uma educação transformadora com base nos princípios do pensamento complexo, tendo em vista que as aulas ofertadas foram além da mera transmissão de informações visando à formação de professores pesquisadores, críticos, reflexivos e atentos às temáticas ambientais.

Submetido em: 08/11/2020 - Aceito em: 16/01/2021 - Publicado em: 25/01/2021

\footnotetext{
${ }^{1}$ Possui graduação em Pedagogia pela Pontifícia Universidade Católica do Paraná (1981), mestrado em Educação pela Pontifícia Universidade Católica do Paraná (1994) e doutorado em Engenharia de Produção pela Universidade Federal de Santa Catarina (2002). Atualmente é Coordenadora do Programa de Pós Graduação Stricto Sensu em Educação, Professora Titular e Professora Permanente do mestrado e doutorado em Educação da Pontifícia Universidade Católica do Paraná.

${ }^{2}$ Possui graduação em Letras - Português e Espanhol pela Pontifícia Universidade Católica do Paraná (2016), especialização em Metodologia do Ensino de Português para Estrangeiro pela Faculdade UNYLEYA (2018) e mestrado em Educação pela Pontifícia Universidade Católica do Paraná (2020).

${ }^{3}$ Possui graduação em Design pela Pontifícia Universidade Católica do Paraná (2002), especialização em Gestão do Design pela Pontifícia Universidade Católica do Paraná, mestrado em Educação pela Pontifícia Universidade Católica do Paraná. Atualmente é doutorando em Educação pela Pontifícia Universidade Católica do Paraná e Ilustrador Membro da SIB - Sociedade dos Ilustradores do Brasil.
} 
Palavras-chave: Aprendizagem Colaborativa. Cartografia Cognitiva. Educação Ambiental. Formação de Professores. Pensamento Complexo.

\section{ABSTRACT}

Since 2012, the Agrinho Program, conceived in 1995, offers permanent training courses in Distance Learning (EAD) to teachers in order to encourage them to research and prepare them for topics of contemporary social relevance through a pedagogical proposal based on in complex thinking. Consequently, this research aims to analyze how the principles of complex thinking are present in the permanent training courses offered by the Agrinho Program, in the Distance Learning modality, to teachers from both public and private schools. This work is classified as a descriptive case study with a qualitative approach, since the data were collected from experiences obtained through different courses provided by the referred program. It is concluded that the pedagogical strategies of Collaborative Learning and Cognitive Cartography adopted in the courses contributed to provide participants with a transformative education based on the principles of complex thinking, considering that the classes offered went beyond the mere transmission of information aimed at training of researchers who are researchers, critics, reflective and attentive to environmental issues.

KEYWORDS: Collaborative Learning. Cognitive Cartography. Environmental education. Teacher training. Complex thinking.

\section{RESUMEN}

Desde 2012, el Programa Agrinho, ideado el 1995, ofrece cursos en la modalidad de educación a distancia (EAD) a docentes a fin de estimularlos a la investigación y prepararlos para temas de relevancia social de la contemporaneidad por medio de una propuesta pedagógica basada en el pensamiento complejo. Por lo tanto, esta encuesta tuvo el objetivo de analizar como los principios del pensamiento complejo se hacen presentes en cursos de formación permanente ofrecidos por el Programa Agrinho, en la modalidad de EAD, a profesores tanto de la red pública como privada. Este trabajo se clasifica como un estudio de caso descriptivo con abordaje cualitativa, puesto que los datos fueron recolectados a partir de experiencias obtenidas por medio de distintos cursos ofrecidos por el referido programa. Se concluye que las estrategias pedagógicas de Aprendizaje Colaborativo y de Cartografía Cognitiva contribuyeron para proporcionar a los participantes una educación transformadora con base en los principios del pensamiento complejo, puesto que los cursos ofrecidos fueron más allá de la mera transmisión de informaciones teniendo en cuenta la formación de profesores investigadores, críticos, reflexivos y atentos a las temáticas ambientales.

PALABRAS ClAVE: Aprendizaje Colaborativo. Cartografía Cognitiva. Educación Ambiental. Formación de Profesores. Pensamiento Complejo.

\section{INTRODUÇÃO}

Não se pode negar a importância do pensamento newtoniano-cartesiano para a consolidação da ciência, porém esse paradigma conservador tem influenciado a educação nos últimos séculos, assentada na memorização e na repetição de conteúdos fragmentados e descontextualizados (MORIN, 2002). O mundo atual passa por uma grave crise paradigmática de natureza global, mas atinge a educação de forma ainda mais grave, dado que esse pensamento conservador 
continua influenciando a formação de novas gerações, com sérias implicações para o futuro da humanidade (SANTOS; OLIVEIRA, 2015; MORAES, 2009).

Por essa razão, entende-se que os paradigmas conservadores necessitam de uma urgente superação, especialmente referente à reprodução do conhecimento, ao papel do professor detentor de verdades prontas e absolutas e do aprendiz como um ser passivo e mero depósito de informações. Neste século, torna-se indispensável que os docentes e os discentes assumam o papel de produtores de novos conhecimentos mais críticos, criativos, reflexivos e autônomos (BEHRENS, 2012).

Para tanto, é importante que o docente construa "propostas educacionais mais coerentes com as demandas atuais, capazes de superar o dualismo cultural, biológico, social e espiritual que tantos problemas têm provocado" (MORAES, 2012, p. 82). Partindo dessas considerações, o Programa Agrinho foi concebido em 1995 com o objetivo de levar informações sobre saúde e segurança pessoal e ambiental, principalmente às crianças do meio rural, consolidando-se como instrumento eficiente na operacionalização de temáticas de relevância social da contemporaneidade dentro dos currículos escolares.

O Programa Agrinho defende uma educação crítica, criativa e reflexiva a fim de que tanto os docentes como os discentes adquiram autonomia, bem como se tornem pesquisadores e produtores de novos conhecimentos. Desde 2012, o referido programa vem ofertando cursos de formação permanente na modalidade de Educação a Distância (EAD) para professores da rede pública e privada a fim de incentivá-los à pesquisa por intermédio de uma proposta pedagógica baseada no pensamento complexo. Ademais, ressalta-se que esse programa utiliza como estratégia pedagógica de educação a distância a Aprendizagem Colaborativa e a Cartografia Cognitiva a fim de preparar os docentes para questões ambientais e temas de relevância social da contemporaneidade, indo além da transmissão de informações por meio do incentivo à colaboração e à construção de Mapas Conceituais, método que possibilita uma organização do conhecimento, de forma mais híbrida, com visão global e simultânea de registro visual gráfico.

Por conseguinte, esta pesquisa tem o objetivo de analisar como os princípios do pensamento complexo se fazem presentes nos cursos de formação permanente ofertados pelo Programa Agrinho, na modalidade de EAD, a professores tanto da rede pública como privada. Este trabalho classifica-se como um estudo de caso descritivo com abordagem qualitativa, uma vez que os dados foram coletados a partir de experiências obtidas por intermédio de diferentes cursos fornecidos pelo referido programa. 


\section{EDUCAÇÃO AMBIENTAL À LUZ DO PENSAMENTO COMPLEXO}

A sociedade atual passa por uma crise antropológica sem precedentes relacionada a uma grave crise de natureza global, implicando diferentes dimensões da vida. A esse respeito, Moraes (2012) defende que o ser humano evoluiu científica e tecnologicamente, mas que esse desenvolvimento não veio acompanhado de uma evolução social, ética, moral e espiritual. Por conseguinte, tal crise é decorrente de pensamentos, ações, valores, hábitos, atitudes e estilos de vida equivocados, pois se encontram focalizados no pensamento newtoniano-cartesiano, que enfatiza o ter, em detrimento do ser.

Não se pode negar que o pensamento newtoniano-cartesiano possibilitou o progresso científico e tecnológico, que facilitou a comunicação e encurtou as distâncias (BEHRENS, 2013). Porém, esse pensamento conservador contaminou a educação com uma visão racionalista, mecanicista, fragmentada e reducionista. Nesta visão, o papel principal do professor é transmitir o conteúdo, por meio de aulas expositivas, na forma de verdade absoluta a ser absorvida e reproduzida pelos discentes, nas palavras de Libâneo (1986).

O atual ensino fragmentado e reducionista atrofia a atitude de contextualizar e globalizar, qualidades fundamentais do espírito humano (MORIN, 2002). Dessa forma, Moraes (2009) defende que a verdadeira causa dessa crise antropológica está no fato de que a maioria dos intelectuais que integram o mundo acadêmico e suas instituições subscreve percepções estreitas da realidade, inadequadas para resolver os atuais problemas da sociedade.

Tendo em vista que o mundo contemporâneo enfrenta problemas complexos, que requerem soluções equivalentes e compatíveis com sua natureza complexa, Morin (2013) defende que há a necessidade de um pensamento capaz de enfrentar o desafio da complexidade do real. Não obstante, para esse autor, compreender as ligações, interações e implicações mútuas, os fenômenos muldimensionais, as realidades simultaneamente solidárias e conflituosas só é possível por meio de uma reforma paradigmática do pensamento.

Filosoficamente, Kuhn (2003) define paradigmas como teorias, fatos, noções científicas aceitas pela comunidade relevante, isto é, são modelos dos quais nascem as tradições coerentes e específicas das pesquisas científicas. A mudança de paradigmas ocorre quando a descoberta de um novo acontecimento pode resultar no descobrimento de irregularidades no antigo, surgindo, assim, uma crise de paradigmas. $\mathrm{O}$ vencedor será o paradigma que mais se adequar à vida comunitária. 
Vale ressaltar que a superação de um paradigma científico não o invalida, não o torna errado ou nulo, apenas evidencia que seus pressupostos não correspondem mais às novas exigências históricas. Na verdade, em consonância com Behrens (2013), o novo paradigma incorpora alguns referenciais significativos do velho paradigma que ainda atendem aos anseios históricos da época.

Foi assim que, gradativamente, ao longo do século XX, o pensamento newtoniano-cartesiano passou a perder força em decorrência de um movimento baseado na proposta de um novo paradigma que busca a conjunção, a inclusão e a diversidade (BEHRENS, 2012). Esse novo paradigma requer a substituição de um pensamento que está separado por outro que está ligado, tornando-se impossível "conceber as partes sem conceber o todo e tampouco o todo sem conceber as partes" (MORIN, 2002, p. 22). Isso porque, nada no universo está isolado, portanto, sem um contexto, nada faz sentido.

Esse novo pensamento é conhecido como paradigma da complexidade, mas também recebe outras denominações tais como emergente, ecológico ou sistêmico. Todas essas propostas buscam a visão do todo, ou da totalidade, dado que, em oposição ao pensamento newtonianocartesiano, o pensamento complexo pressupõe colocar o conhecimento no contexto de um todo mais amplo a fim de melhor compreendê-lo (CAPRA, 1996). Assim sendo, o paradigma da complexidade aparece como um movimento global que tem como eixo norteador conscientizar a humanidade no sentido de viver de maneira ética, responsável e sustentável em busca da construção de um mundo melhor, mais justo e solidário (BEHRENS, 2012).

Opondo-se à lógica binária excludente, a lógica ternária apresenta-se como a nova base dos fundamentos da ciência, a qual permite ao professor trabalhar a partir de uma lógica tripartida para desenvolver suas construções teóricas e práticas pedagógicas (MORAES, 2012). Com essa lógica ternária, que reconhece uma terceira possibilidade além das existentes, há uma superação da ontologia baseada no dualismo e na fragmentação do conhecimento.

Em sua dimensão epistemológica, diferente do pensamento newtoniano-cartesiano, os fundamentos científicos e filosóficos do paradigma da complexidade reconhecem a existência de múltiplas realidades e diferentes níveis de realidade regidos por distintos níveis de materialidade, nas palavras de Moraes (2012). Isso quer dizer que, conforme Morin (2013), não existe verdade absoluta, pois todo conhecimento implica risco de erros e de ilusões devido às limitações dos sentidos humanos e dos dispositivos cognitivos.

Essa mudança de paradigma na ciência leva o professor a repensar a prática pedagógica oferecida aos educandos, demandando uma formação docente que tenha como base as 
exigências de paradigmas inovadores (SANTOS; OLIVEIRA, 2015). Contudo, alcançar uma educação transformadora requer que a sociedade contemporânea adote novas práticas pedagógicas capazes de conectar não apenas os diferentes saberes, mas também as diversas dimensões do triângulo da vida (indivíduo - sociedade - natureza), consoante Moraes (2012) e Morin (2011).

Foi nesse contexto de crise que, no final do século $\mathrm{XX}$, a educação ambiental surgiu e se consolidou decorrente da demanda de que o ser humano adotasse uma visão de mundo e uma prática social capazes de minimizar os impactos ambientais. Não obstante, Layrargues e Lima (2014) ressaltam que, para além de uma educação ecológica, a educação ambiental também compreende um universo pedagógico complexo e multidimensional que gira em torno das relações estabelecidas entre o indivíduo, a sociedade, a educação e a natureza.

Em vista disso, as Diretrizes Curriculares Nacionais Gerais da Educação Básica, de 2013, reconhece a relevância e a obrigatoriedade da educação ambiental em todos os seus níveis e modalidades (BRASIL, 2013). A esse respeito, Imbernón (2016, pp. 51-52) ressalta que não será possível enfrentar o futuro

[...] sem ensinar e aprender a complexidade de ser cidadão e as diversas sensibilidades nas quais se materializa: democrática, social, solidária, igualitária, intercultural e relativa ao meio ambiente. E isso será aprendido na escola. [...] nesta sociedade haverá muitos aspectos importantes que só poderão ser aprendidos nas escolas; entre eles, a de ser um cidadão que respeite a si mesmo e aos outros, sejam eles quem forem, bem como a seu ambiente.

Levando em consideração que os professores dos diferentes níveis e modalidades de ensino precisam abordar a dimensão ambiental em sala de aula, torna-se irrefutável que eles tenham uma formação docente que lhes permita proporcionar a seus discentes uma educação ambiental articulada às diversas áreas do conhecimento. Desse modo, torna-se necessário apresentar o conceito de formação de professores adotado nesta pesquisa que se refere à

[...] área de conhecimentos, investigação e de propostas teóricas e práticas que, no âmbito da Didática e da Organização Escolar, estuda os processos através dos quais os professores - em formação ou em exercício - se implicam individualmente ou em equipa, em experiências de aprendizagem através das quais adquirem ou melhoram os seus conhecimentos, competências e disposições, e que lhes permite intervir profissionalmente no desenvolvimento do seu ensino, do currículo e da escola, com o objetivo de melhorar a qualidade da educação que os alunos recebem (MARCELO, 1999, p. 26).

Em outras palavras, Marcelo (1999) defende que a formação de professores é um processo contínuo que se inicia na Educação Básica e se estende ao longo da vida profissional docente. Ademais, a formação docente abrange uma dimensão ontológica, uma vez que precisa se 
adequar às mudanças sociais, econômicas e históricas. A formação de professores também se articula com a organização do sistema educacional e institucional, pois as universidades e os centros de formação carecem desenvolver atividades colaborativas centradas na escola. Outro princípio importante, descrito pelo autor espanhol, é que a formação docente vincula conhecimentos teóricos e práticos, bem como busca a similaridade entre a formação recebida pelos docentes e sua prática posterior.

Ainda de acordo com Marcelo (1999, pp. 25-26), a formação docente é um processo de caráter sistemático e organizado, que envolve quatro fases:

a) Pré-treino: é a fase que antecede a formação propriamente dita e que inclui as experiências prévias de ensino que os candidatos a professor viveram como estudantes, as quais podem ser assimiladas de uma forma acrítica e influenciar de um modo inconsciente a prática pedagógica do futuro professor.

b) Formação inicial: é a fase de preparação formal em uma instituição específica e devidamente credenciada para a formação de professores.

c) Inserção profissional: corresponde aos primeiros anos de exercício profissional docente, durante os quais o professor assume a profissão em sua plenitude.

d) Formação permanente: é a fase que permite ao professor o desenvolvimento profissional e o aperfeiçoamento de seu ensino, quer pela prática profissional quer pela participação em cursos ou programas de formação docente.

Considerando que muitos professores tendem a reproduzir as práticas vividas durante sua história de vida (TARDIF, 2000), o método de formação docente torna-se tão importante quanto o conteúdo a ser ministrado (IMBERNÓN, 2016). Desse modo, é imprescindível que os professores tenham uma formação que lhes permita promover uma educação ambiental que, para além de uma educação meramente ecológica, também leve em conta as relações estabelecidas entre o indivíduo, a sociedade e a natureza.

\section{APRENDIZAGEM COLABORATIVA E CARTOGRAFIA COGNITIVA NA EAD}

$\mathrm{Na}$ atualidade existe uma crescente demanda de formação inicial e permanente. Contudo, os atuais sistemas educativos formais têm-se apresentado incapazes de atender às necessidades educacionais tanto quantitativas como qualitativas. Em vista disso, reclama-se uma mudança de paradigma pedagógico, no qual o centro da educação passe do ensino para o aprendizado. Para responder aos novos desafios da mudança de paradigmas, os sistemas educativos são 
obrigados a diversificar a oferta educativa (GASPAR, 2001). É nesse contexto que o século XX encontrou na Educação a Distância (EAD) uma alternativa às exigências sociais e pedagógicas, contando com o apoio dos avanços das tecnologias digitais de informação e comunicação (PRETI, 1996).

Essa modalidade educacional passou a ocupar uma posição instrumental estratégica para satisfazer as amplas e diversificadas necessidades de qualificação das pessoas adultas. Diversas pesquisas sobre as experiências de EAD no mundo vêm apontando que essa é uma modalidade de educação eficaz para atender não apenas à população que, embora não o seja legalmente, na prática é excluída do ensino presencial, como também a todos os cidadãos que necessitam de formações distintas ou pretendem ter acesso a uma formação inicial e permanente (PRETI, 1996).

O uso das tecnologias digitais de informação e comunicação permite aos cursos de EAD atender de modo concreto às necessidades e expectativas da clientela, favorecendo a inclusão social, a flexibilidade, a comodidade e a praticidade (BELLONI, 2009). Não obstante, para permitir ao estudante aprender como, onde e quando ele quiser, o sistema adotado pelos cursos de EAD precisa oferecer, efetivamente, diferentes mecanismos de comunicação multidirecional, os quais permitem o enriquecimento dos recursos de aprendizagem. É por essa razão que os cursos fornecidos pelo Programa Agrinho na modalidade de EAD adotam as estratégias pedagógicas de Aprendizagem Colaborativa e de Cartografia Cognitiva.

Na metodologia da Aprendizagem Colaborativa são criadas situações de interdependência em que os membros do grupo só conseguem realizar seus objetivos pessoais se o grupo como um todo for bem-sucedido, nas palavras de Campos et al. (2003). Essas situações contribuem para que os estudantes se tornem mais responsáveis pela sua própria aprendizagem e pela aprendizagem de seus colegas, dado que todos os estudantes envolvidos nessa metodologia "são automaticamente responsáveis por seu progresso e pelo progresso do seu grupo, num relacionamento solidário e sem hierarquias" (TORRES; IRALA, 2014).

Uma das ideias fundamentais da Aprendizagem Colaborativa é a de que o conhecimento é construído socialmente, por meio da participação ativa e da interação tanto dos docentes como dos discentes (CAMPOS et al., 2003). Dessa forma, para Torres e Irala (2014), essa metodologia rejeita fortemente a metodologia de reprodução do conhecimento, que coloca o discente como sujeito passivo do processo de ensino-aprendizagem.

Levando em conta que na Aprendizagem Colaborativa o conhecimento não acontece pela transferência do professor ao estudante, essa metodologia tem o potencial de promover uma 
aprendizagem mais ativa por meio do estímulo ao pensamento crítico, ao desenvolvimento de capacidades de interação, solidariedade, respeito mútuo e autorregulação do processo de ensino-aprendizagem (TORRES; IRALA, 2014; TORRES; MARRIOTT, 2006). Além do mais, a metodologia da Aprendizagem Colaborativa gera vantagens significativas para os estudantes, pois incentiva a autonomia, o respeito ao pensamento dos outros membros do grupo, visando ao enriquecimento da aprendizagem individual pelas experiências de aprendizagem de cada membro do grupo, consoante Campos et al. (2003).

Por sua vez, a Cartografia Cognitiva consiste na representação de mapas do conhecimento para pesquisa, aprendizagem e formação docente. Esse recurso tem o propósito de sintetizar e ilustrar caminhos propositivos, visualização e análise de categorias e fixação de conteúdos, uma vez que a narrativa visual, ilustrada por meio de mapas mentais e conceituais, contribui enquanto estratégia de estudo.

Ao longo do século, muitos pensadores, escritores e artistas utilizaram o recurso do desenho como elemento de conexão, transformando conteúdo abstrato em concreto, fala em imagens, texto transformado em esquemas gráficos e recursos visuais de síntese. Victor Papanek (19231999), arquiteto e designer, considerado referência no desenvolvimento de um desenho universal mais humano foi um deles, pois questionava as relações existentes em um Design complexo e suas consequências ao meio ambiente e necessidades humanas. Victor Papanek utilizava mapas conceituais como forma de registro de síntese na organização cognitiva.

O Mapa Conceitual, conforme figura abaixo, é um tipo específico de Cartografia Cognitiva que facilita o acompanhamento e o desenvolvimento da estrutura cognitiva, contribuindo com a migração de um ensino memorístico para um ensino significativo, sendo uma técnica poderosa de ensino e aprendizagem. De acordo com Marriott e Torres (2015), os Mapas Conceituais apresentam alguns benefícios para o estudante, pois o ajuda a desenvolver as estratégias de leitura e as habilidades linguísticas, bem como lhe possibilita praticar a análise do texto como um todo, compreendendo-o tanto em sua microestrutura como em sua macroestrutura. 
Figura 1. Mapa Conceitual sobre Mapas Conceituais.

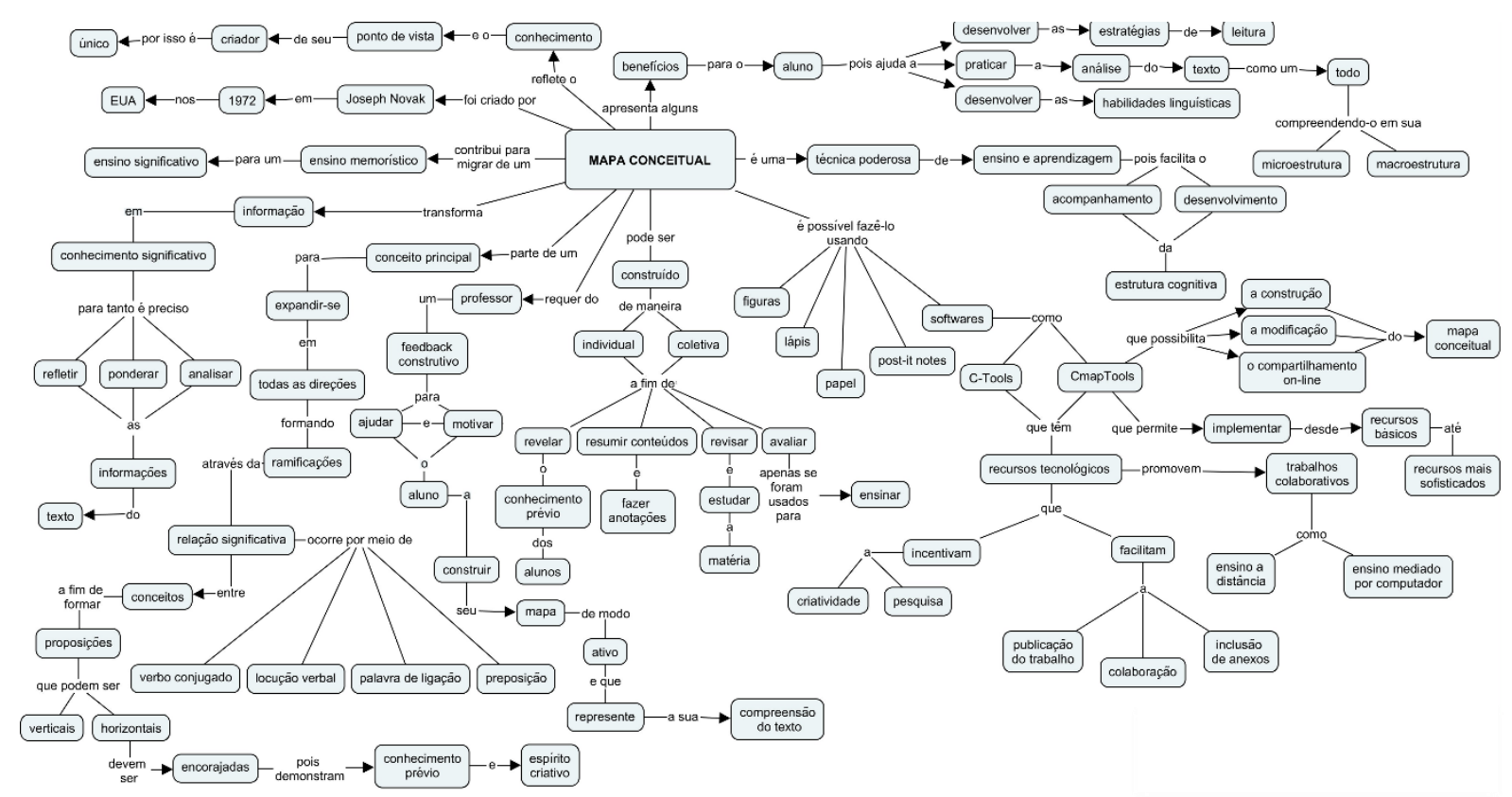

Fonte: Professora participante de formação (2020).

Os Mapas Conceituais podem ser construídos de maneira individual ou coletiva a fim de revelar o conhecimento prévio dos estudantes, resumir conteúdos por meio de anotações, assim como revisar e estudar determinadas matérias. É possível construir Mapas Conceituais usando figuras, lápis, papel, post-it note e softwares como o C-Tools e o CmapTools, que têm recursos tecnológicos que incentivam a criatividade e a pesquisa. Os supramencionados softwares também facilitam a publicação do trabalho, a colaboração e a inclusão de textos (MARRIOTT; TORRES, 2015).

O crescente uso de recursos visuais como estratégia de representação da informação possibilita ao estudante utilizar o desenho/ilustração como um objeto-escrita de autoralidade e síntese de informação, fazendo com que ele produza seu próprio conhecimento. Ademais, proporciona flexibilidade aos conteúdos e aproxima leitores de narrativas e ideias, bem como oferece a professores e formadores de opinião um elemento de sensibilização e metodologia flexível. 


\section{METODOLOGIA}

Este trabalho classifica-se como um estudo de caso descritivo com abordagem qualitativa. Do ponto de vista dos procedimentos técnicos, o estudo de caso "consiste no estudo profundo e exaustivo de um ou poucos objetos, de maneira que permita seu amplo e detalhado conhecimento" (GIL, 2010, p. 37). De forma complementar, Pimentel (2011, p. 434) defende que o estudo de caso é

[...] um método de pesquisa empírica para investigar a ocorrência de um fenômeno num contexto real. [...] o estudo de caso é um método para avaliar se a teoria se verifica na prática, é adequado quando se busca o realismo contextualizado em vez da precisão laboratorial livre de contexto.

Para analisar como os princípios do pensamento complexo se fazem presentes em cursos de formação permanente de professores ofertados pelo Programa Agrinho na modalidade de EAD, foi necessário fazer uma investigação em um contexto real. Isso requereu que a coleta de dados fosse feita a partir de experiências obtidas por intermédio de diferentes cursos fornecidos pelo referido programa, que visam à formação permanente de professores críticos, reflexivos e atentos às temáticas ambientais por meio das estratégias pedagógicas de Aprendizagem Colaborativa e de Cartografia Cognitiva, que incentivam a colaboração e a construção de Mapas Conceituais. Assim sendo, este estudo de caso classifica-se como descritivo, uma vez que fez uso de dados e fatos colhidos da própria realidade (CERVO; BERVIAN; SILVA, 2007).

Em consenso com Cervo, Bervian e Silva (2007, p. 50), a pesquisa descritiva “[...] deve ser bem planejada se quiser oferecer resultados úteis e fidedignos. Esse planejamento envolve também a tarefa de coleta de dados [...]”. Para esses autores, entre os diferentes instrumentos existentes, os dados da pesquisa descritiva costumam ser coletados por meio de questionários. Levando em conta que esta pesquisa teve o ambiente natural como sua fonte direta de dados e o pesquisador como seu principal instrumento de coleta de dados, do ponto de vista do problema da pesquisa adotou-se a abordagem qualitativa (OLIVEIRA, 2013).

Ressalta-se que "o desenvolvimento da teoria, anterior à coleta de qualquer dado, é um passo essencial na realização dos estudos de caso" (YIN, 2010, pp. 58-59), já que a fundamentação teórica facilita a fase da interpretação das informações obtidas. Desse modo, este estudo de caso descritivo buscou embasamento teórico em estudiosos como: Behrens (2012) e (2013); Imbernón (2016); Marcelo (1999); Marriott e Torres (2015); Moraes (2009) e (2012); Morin (2002) e (2013); Santos e Oliveira (2015); Torres e Irala (2014); Torres e Marriott (2006). 
No primeiro semestre de 2020, diferentes cursos de formação permanente de professores foram ofertados pelo Programa Agrinho na modalidade de EAD com o objetivo de aumentar o acesso às bases teóricas, utilizando como estratégia pedagógica a Aprendizagem Colaborativa e a Cartografia Cognitiva. Após o término dos cursos, que tiveram carga horária de 40 horas, os dados foram coletados por meio de um questionário com quatro questões abertas, junto a 113 professores da rede pública e privada.

Primeiramente, os dados coletados foram organizados e submetidos a uma análise prévia a fim de observar falhas, distorções e erros. Depois de selecionar as informações passíveis de análise e interpretação, o passo seguinte foi a codificação dos 113 participantes, identificados entre P1 a P113, bem como a observação das respostas similares ou convergentes. Os dados obtidos foram transcritos e organizados em tabelas. Por último, tendo como referencial a teoria fundamentada no marco teórico, foi possível propor inferências, bem como adiantar interpretações com base no objetivo previsto.

\section{ANÁLISE DOS RESULTADOS}

A primeira questão do questionário pedia aos professores que avaliassem sua aprendizagem por meio da proposta de Aprendizagem Colaborativa. Após a pré-análise e a exploração dos dados obtidos, algumas das respostas a essa pergunta aberta foram selecionadas e transcritas abaixo para facilitar a análise e interpretação dos dados obtidos.

P2 - Podemos promover a aprendizagem colaborativa organizando a sala de aula em grupos ordenados, criando situações de aprendizagem e que sejam favorecidas trocas entre alunos e professor de forma significativa. Assim todos os alunos participantes dessa aprendizagem colaborativa são responsáveis pelo sucesso do grupo e também se envolvem solidariamente e sem hierarquias.

P6 - Claro que o assunto não era exatamente novo, mas sempre se pode aprender mais de tudo. As leituras e atividades me proporcionaram boas reflexões, mesmo porque nem sempre paramos para refletir sobre nossa prática.

P8 - A troca de experiência, as interações com outros colegas de trabalho foram de grande importância para estimular o pensamento e aprofundar de certa forma o entendimento sobre os assuntos abordados. Além disso, essa metodologia permitiu de certa forma que desenvolvêssemos uma aprendizagem mais ativa, crítica e autônoma.

P17 - As leituras dos materiais de apoio proporcionaram uma aprendizagem significativa. Ao ler a interação dos colegas sobre as práticas desenvolvidas em sala percebe-se que as dificuldades são as mesmas e nos sentimos mais solidários e perseverantes diante das dificuldades enfrentadas em sala de aula. 
P19 - Avaliei como positiva minha aprendizagem, pois o curso permitiu uma reflexão sobre aprendizagem colaborativa e sobre os mapas conceituais. Com certeza em minha prática pedagógica essas reflexões oportunizarão mudanças no dia a dia de sala de aula.

P85 - Percebi que por meio de situações criadas em sala de aula, pode-se despertar o aluno para discussão de temas diversos, tomada de decisão, observação e críticas em torno do trabalho em andamento e ainda proporcionar a construção de transformações que só é possível ao compartilhar conhecimentos e saberes dentro de um fazer coletivo.

P106 - Contribuiu muito para a minha prática docente, pois me fez repensar como estava meu trabalho docente.

De acordo com o P2 e o P17, ao transferir a responsabilidade de aprendizado aos estudantes, a metodologia da Aprendizagem Colaborativa contribuiu para que tanto os docentes como os discentes se envolvessem uns com os outros sem hierarquias, a fim de construir um mundo mais solidário e igualitário. A interação entre pares, promovida pela Aprendizagem Colaborativa, foi importante para estimular o pensamento crítico dos participantes, em especial do P8 e do P85, bem como sua autonomia.

Além disso, por meio dos relatos do P6, do P19 e do P106 foi possível perceber que a Aprendizagem Colaborativa permitiu aos professores repensar sua prática pedagógica por meio da reflexão de questões ambientais e de temas de relevância social da contemporaneidade, conectando não apenas os diferentes saberes, mas também as diversas dimensões do triângulo da vida (indivíduo - sociedade - natureza).

Assim sendo, percebe-se que essa estratégia vai ao encontro dos princípios do pensamento complexo, pois busca educar para a vida por meio do desenvolvimento das dimensões social, interpessoal, pessoal e profissional dos docentes em formação a fim de que eles sejam capazes de enfrentar o desafio da complexidade do real e de se comprometer com a melhoria da sociedade atual.

A segunda questão do questionário de pesquisa pedia aos professores em formação permanente que descrevessem as vantagens do uso de Mapas Conceituais. Após realizar a pré-análise e a exploração dos dados obtidos, algumas das respostas a essa pergunta aberta foram selecionadas e transcritas abaixo a fim de facilitar sua análise e interpretação.

P2 - Na tentativa de obter êxito, o professor utiliza os Mapas Conceituais, uma técnica que encoraja o aluno a refletir, a pesquisar, a selecionar, a analisar, a elaborar o conhecimento e aprender de uma maneira significativa, essa técnica é utilizada em escolas, universidades e em empresas em todo o mundo. 
P32 - O mapa conceitual proporciona a visão geral de um todo.

P33 - Uma das grandes vantagens é partir daquilo que o aluno já sabe e outra é que faz com que o aluno reflita, pense, pondere, pesquise novamente se houver necessidade e por fim tire suas conclusões.

P34 - Desenvolve melhor o senso crítico do aluno, incentivando-o na busca de materiais que o leve à aprendizagem.

P42 - Como o próprio nome diz "MAPA", com ele conseguimos visualizar melhor o todo e buscar as particularidades.

P43 - É uma técnica muito interessante para desenvolver e mostrar assuntos (conteúdos), que ajudam o aluno a ver um ensino mais transparente; revelando o conhecimento do mesmo para desenvolver um módulo, revisar e estudar a matéria. E todas essas atividades incentivam o pensamento crítico e criativo, estimulam o desenvolvimento do aluno; reforçando sua compreensão e suas habilidades na aprendizagem.

P48 - Os mapas permitem uma melhor compreensão do conteúdo estudado, pois você tem uma visão do todo. Permite visualizar os links de uma forma mais clara. É ótimo para quem gosta de esquemas. E o principal permite a quem usa ser criativo, e usar a imaginação de uma forma lúdica, sem perder a cientificidade.

P51 - Os mapas conceituais permitem uma visão ampla na construção do conhecimento, pois permite a interação entre os conhecimentos empíricos e os conhecimentos científicos, o que auxiliam na construção coletiva do processo de ensino e aprendizagem.

P58 - Com poucas palavras você tem a visão do todo.

P61 - Proporciona uma visão ampla do assunto.

P66 - São muitas as vantagens, pois facilita a elaboração de questionamentos, onde os alunos tem uma visão ampla, para uma melhor relação entre os conceitos na construção do conhecimento. As estratégias facilitam a compreensão dos alunos através da pesquisa, para a elaboração dos conteúdos e assimilação dos mesmos.

P67 - O conteúdo é construído e não apenas memorizado, o que propicia uma real aprendizagem e não apenas a memorização, que em geral tem curta duração.

P75 - Os mapas conceituais podem facilitar a aprendizagem do aluno e o entendimento de conteúdos, proporcionando uma visão integrada dos assuntos, com interdisciplinaridade.

P88 - Os mapas conceituais a meu ver permitem uma síntese do conteúdo estudado ou pesquisado; permite estabelecer relações significativas entre os conceitos e, uma visão da totalidade do conhecimento abordado.

P97 - Desenvolve um olhar crítico e reflexivo para o assunto, interligando vários conhecimentos. 
Segundo o P2, o P33, o P34, o P43, o P48 e o P97, o uso de Mapas Conceituais lhes permitiu refletir sobre os atuais problemas da realidade, bem como incentivou o pensamento crítico e criativo. Essa estratégia pedagógica deu aos docentes a oportunidade de assumir o papel de produtores do conhecimento por meio da pesquisa, deixando de serem vistos como seres passivos e meros depósitos de informações, o que já é um passo para a superação do pensamento newtoniano-cartesiano.

Outra vantagem dos Mapas Conceituais que remete aos princípios do pensamento complexo é que eles proporcionam uma visão do todo, levando à construção do conhecimento por meio da conexão de diferentes saberes. De acordo com o P42, o P48, o P51, o P58, o P61, o P66, o P75, o P88 e o P97, os Mapas Conceituais permitiram estabelecer relações significativas entre os conceitos e, consequentemente, uma visão da totalidade dos assuntos abordados.

Ressalta-se que identificar conceitos e estabelecer relações entre eles não garante o desenvolvimento do pensamento complexo, porém, por meio do relato dos participantes, em especial do P67, percebe-se que aprender a fazer Mapas Conceituais proporcionou aos professores uma formação voltada à educação ambiental articulada às diversas áreas do conhecimento, o que remete ao princípio de transdisciplinaridade do pensamento complexo.

A terceira questão do questionário de pesquisa pedia aos participantes que apontassem seus ganhos no que diz respeito à apreensão e à construção do conhecimento com a proposta de Aprendizagem Colaborativa. Depois de realizar a pré-análise e a exploração dos dados obtidos, algumas das respostas a essa pergunta aberta foram selecionadas e transcritas abaixo a fim de facilitar sua análise e interpretação.

P9 - Professores e alunos só tendem a ganhar, pois quando ambos interagem, os alunos aprendem trabalhar em grupos, tornam-se mais autônomos e críticos, aumenta o rendimento escolar entre outros pontos positivos.

P10 - Interação com todos os alunos; Participação da maioria; Formação de conceitos de forma mais autônoma.

P33 - A aprendizagem colaborativa leva a aprendizagem através da interação e com responsabilidade de ambas as partes não sobrecarregando ninguém. Melhora o entendimento sobre determinado assunto somando a troca de ideias do grupo.

P43 - Na aprendizagem colaborativa temos a ganhar com o conhecimento e troca mútua de ideias, interagindo em grupos, discutindo, refletindo e trocando as experiências; cada um dos participantes compartilha de responsabilidades, de interação permanente com o grupo; com o objetivo de produzir novos conhecimentos.

P46 - Estimula o pensamento crítico, desenvolvimento de capacidades de interação, negociação de informações e resolução de problemas e a capacidade de 
autorregulação do processo de ensino-aprendizagem. Os alunos são estimulados a construir conhecimentos de uma maneira mais autônoma. O conhecimento é construído socialmente, na interação entre pessoas e não pela transferência do professor para o aluno.

P61 - Desenvolve valores de ética e cidadania, uma vez que essa aprendizagem está preocupada em formar alunos com visão construtiva, voltando suas atividades a trabalhos que envolvam a vida pessoal e a comunidade, baseados em cooperação, respeito, responsabilidades e solidariedade.

P71 - Acredito que os ganhos profissionais sejam os mesmos apontados pelos alunos, com um novo posicionamento e relacionamento entre discente e docente. Facilita a visão geral e específica do conteúdo a ser abordado. Colabora para o enfoque daquilo que está sendo apontado como aprendizagem efetiva. Possibilita novos caminhos, e entrelaça conteúdos que são inerentes ao objetivo geral, (conteúdos interdisciplinares e transdisciplinares). Possibilita aprendizagem globalizada, integrada e holística. Assegura que a aprendizagem está acontecendo de acordo com a maturidade do grupo. Ampara o professor e o instiga a ser um pesquisador, e como tal, motiva seus alunos.

P102 - Humanização, socialização do conhecimento, respeito ao outro, organização do trabalho e responsabilidade pelo que se faz.

Por intermédio dos relatos do P33, do P43, do P61, P71 e do P102 foi possível perceber que os cursos de formação permanente analisados adotam práticas pedagógicas capazes de conectar não apenas os diferentes saberes, mas também de estabelecer relações entre o indivíduo, a sociedade e a natureza. Tais participantes relataram que a Aprendizagem Colaborativa os levou à aprendizagem globalizada por meio da interação e respeito a si mesmo, aos outros e ao meio ambiente.

Por sua vez, conforme o P9, o P10 e o P46, as estratégias pedagógicas adotadas nos cursos estimularam-nos a construir novos conhecimentos de forma mais autônoma e crítica por meio da interação entre pares e não pela transferência do docente para o discente. Em vista disso, percebe-se que esses participantes tiveram acesso a uma educação transformadora com base nas exigências do paradigma da complexidade.

Os professores tiveram que aplicar em sala de aula com seus discentes os conceitos sobre mapas conceituais aprendidos no curso de formação permanente. Assim sendo, a quarta e última questão do questionário de pesquisa pedia aos docentes que relatassem se acreditavam que seu processo de ensino-aprendizagem com o uso de mapas conceituais havia melhorado ou não. Após realizar a pré-análise e a exploração dos dados obtidos, algumas das respostas a essa pergunta aberta foram selecionadas e transcritas abaixo a fim de facilitar sua análise e interpretação.

P8 - Com certeza, esse é um recurso do qual já fazia uso em minhas aulas. Mas após as reflexões proporcionadas pelas atividades do curso, pude aprimorar minha prática 
em sala de aula, os alunos passaram a entender melhor a importância deste recurso na construção de uma aprendizagem mais significativa, ou seja, uma maneira melhor de assimilar uma informação e transformá-la em conhecimento.

P46 - A partir da reflexão e da compreensão de que ao professor não basta apenas passar o conteúdo de forma pronta e acabada, mas sim criar situações de aprendizagem em que possam ocorrer trocas significativas entre os alunos e entre estes e o professor. $\mathrm{O}$ desafio é transformar essa informação em conhecimento. O desafio é encontrar meios que auxiliem nesse processo de migração de um ensino memorístico para um ensino significativo. O desafio é educar para formar cidadãos com espírito crítico, promovendo a iniciativa, a responsabilidade e a autoconfiança.

P48 - O uso de mapas conceituais permite ao docente ser mais flexível nas avaliações, pois respeita a individualidade (percepção de cada aluno).

P51 - Houve maior participação e interesse dos alunos durante as aulas, pois os mesmos se sentiram sujeitos ativos do processo de ensino e não somente receptores passivos do conhecimento.

Por meio dos relatos do P8, do P46, do P48 e do P51, foi possível perceber que os Mapas Conceituais melhoraram significativamente a aprendizagem tanto dos professores em formação como de seus discentes, dado que a conclusão dos cursos requeria que os conceitos aprendidos fossem colocados em prática, buscando a similaridade entre a formação recebida pelos docentes e sua prática posterior. Essa atividade final, proporcionou aos participantes a oportunidade não apenas de refletir sobre sua prática pedagógica, mas também de modificá-la a fim de formar cidadãos críticos, responsáveis e capazes de enfrentar o desafio da complexidade do real.

\section{CONSIDERAÇÕES FINAIS}

O objetivo desta pesquisa foi alcançado, uma vez que foi possível analisar como os princípios do pensamento complexo se fazem presentes nos cursos de formação permanente ofertados pelo Programa Agrinho, na modalidade de EAD, a professores tanto da rede pública como privada. As estratégias pedagógicas adotadas nos referidos cursos vão ao encontro dos princípios do pensamento complexo, pois buscam educar para a vida por meio do desenvolvimento das dimensões social, interpessoal, pessoal e profissional dos docentes em formação a fim de que eles sejam capazes de enfrentar o desafio da complexidade do real e de se comprometer com a melhoria da sociedade atual.

Ao transferir a responsabilidade de aprendizado aos estudantes, a Aprendizagem Colaborativa e a Cartografia Cognitiva permitiram aos professores não apenas repensar sua prática pedagógica por meio da reflexão dos problemas da sociedade atual, mas também contribuíram 
para estimular a autonomia, o pensamento crítico e criativo. Essas estratégias pedagógicas deram aos docentes o acesso a uma educação transformadora com base nos princípios do pensamento complexo, tendo em vista que eles assumiram o papel de produtores de novos conhecimentos por meio da pesquisa, deixando de serem vistos como seres passivos e meros depósitos de informações.

A Aprendizagem Colaborativa e a Cartografia Cognitiva proporcionaram uma aprendizagem globalizada por meio da interação e respeito a si mesmo, aos outros e ao meio ambiente, bem como buscaram conectar os diferentes saberes, estabelecendo relações entre o indivíduo, a sociedade e a natureza a fim de proporcionar aos professores uma formação voltada à educação ambiental articulada às diversas áreas do conhecimento, o que remete à totalidade e à transdisciplinaridade, princípios do pensamento complexo.

Ressalta-se que em apenas 40h de curso não é viável desenvolver o pensamento complexo, pois esse processo de reforma epistemológica demanda tempo e reflexão. Não obstante, o programa Agrinho apresentou propostas educacionais coerentes com as demandas atuais, capazes de superar o dualismo e a fragmentação ocasionados pelo pensamento newtoniano-cartesiano, uma vez que demonstrou o potencial de preparar os participantes para questões ambientais e temas de relevância social da contemporaneidade, indo além da mera transmissão de informações.

\section{REFERÊNCIAS}

BEHRENS, Marilda Aparecida. Docência universitária no paradigma da complexidade: caminho para a visão transdisciplinar. In: MAGALHÃES, Solange Martins Oliveira; SOUZA, Ruth Catarina Cerqueira Ribeiro de (Orgs.). Formação de professores: elos da dimensão complexa e transdisciplinar. Goiânia: Ed. da PUC Goiás, 2012.

BEHRENS, Marilda Aparecida. O paradigma emergente e a prática pedagógica. 5 ed. Petrópolis: Vozes, 2013.

BELLONI, Maria Luiza. Educação a distância. Campinas, SP: Autores associados, 2009.

BRASIL. Ministério da Educação. Secretaria de Educação Básica. Secretaria de Educação Continuada, Alfabetização, Diversidade e Inclusão. Conselho Nacional da Educação.

Diretrizes Curriculares Nacionais Gerais da Educação Básica. Secretaria de Educação Básica. Diretoria de Currículos e Educação Integral. Brasília: MEC, SEB, DICEI, 2013. Disponível em: <http://portal.mec.gov.br/docman/julho-2013-pdf/13677-diretrizes-educacaobasica-2013-pdf/file>. Acesso em: 31 out. 2018. 
CAMPOS, Fernanda Cláudia Alves et al. Cooperação e aprendizagem on-line. Rio de Janeiro: DP\&A, 2003.

CAPRA, Fritjof. Ecologia profunda - um novo paradigma. In: CAPRA, Fritjof. A teia da vida: uma nova compreensão cientifica dos sistemas vivos. São Paulo: Cultrix, 1996, pp. 2345 .

CERVO, Amado Luiz; BERVIAN, Pedro Alcino; SILVA, Roberto da. Metodologia científica. 6. ed. São Paulo: Pearson Prentice Hall, 2007.

GASPAR, Maria Ivone (Org.). Ensino a distância e ensino aberto: paradigmas e perspectivas. In: GASPAR, Maria Ivone (Org.). Discursos: perspectivas em educação, $n .^{\circ}$ especial da revista Discursos. Lisboa: Gráfica Europam, 2001, pp.67-76.

GIL, Antônio Carlos. Como elaborar projetos de pesquisa. 5. ed. São Paulo: Atlas, 2010.

IMBERNÓN, Francisco. Qualidade do ensino e formação do professorado: uma mudança necessária. São Paulo: Cortez, 2016.

KUHN, Thomas. A natureza e a necessidade das revoluções científicas. In: KUHN, Thomas. A estrutura das revoluções científicas. São Paulo: Perspectiva, 2003, pp. 125-145.

LAYRARGUES, Philippe Pomier; LIMA, Gustavo Ferreira da Costa. As macrotendências político-pedagógicas da educação ambiental brasileira. Ambiente \& Sociedade, São Paulo, v. XVII, n. 1, pp. 23-40, jan./mar. 2014. Disponível em:

<http://www.scielo.br/pdf/asoc/v17n1/v17n1a03.pdf>. Acesso em: 16 ago. 2018.

LIBÂNEO, José Carlos. Tendências pedagógicas na prática escolar. In: LIBÂNEO, José Carlos. Democratização da escola pública. São Paulo: Loyola, 1986, pp. 11-44.

MARCELO, Carlos García. Formação de professores para uma mudança educativa. Portugal: Porto Editora, 1999.

MARRIOTT, Rita; TORRES, Patrícia Lupion. Mapas conceituais uma ferramenta para a construção de uma cartografia do conhecimento. In: TORRES, Patrícia Lupion. Complexidade: redes e conexões na produção do conhecimento. Curitiba: SENAR - PR, 2015.

MORAES, Maria Cândida. Paradigma educacional emergente. 9 ed. Campinas, SP: Papirus, 2009.

MORAES, Maria Cândida. Transdisciplinaridade e educação. In: MAGALHÃES, Solange Martins Oliveira; SOUZA, Ruth Catarina Cerqueira Ribeiro de (Orgs.). Formação de 
professores: elos da dimensão complexa e transdisciplinar. Goiânia: Ed. da PUC Goiás, 2012.

MORIN, Edgar. A via para o futuro da humanidade. Tradução de Edgard de Assis Carvalho e Mariza Perassi Bosco. Rio de Janeiro: Bertrand Brasil, 2013.

MORIN, Edgar. Educação e complexidade: os sete saberes necessários e outros ensaios. São Paulo: Cortez, 2002.

MORIN, Edgar. Os sete saberes necessários à educação do futuro. Tradução de Catarina Eleonora F. da Silva e Jeanne Sawaya. 2 ed. São Paulo: Cortez; Brasília, DF: UNESCO, 2011.

OLIVEIRA, Maria Marly de. Como fazer pesquisa qualitativa. 5. ed. Petrópolis, RJ: Vozes, 2013.

PAPANEK, Victor. Design for the real world. New York: Pantheon Books, 1971.

Disponível em: <\&lt;http://playpen.icomtek.csir.co.za/\%7Eacdc/education/Dr_Anvind_ Gupa/Learners_Library_7_March_2007/Resources/books/designvictor.pdf\&gt>. Acesso em: 29 jan. 2018.

PIMENTEL, Mariano. Estudo de caso em sistemas colaborativos. In: PIMENTEL, Mariano; FUKS, Hugo (Orgs.). Sistemas colaborativos. Rio de Janeiro: Elsevier, 2011, pp. 433-448.

PRETI, Oreste (Org.). Educação a distância: uma prática educativa mediadora e mediatizada. In: PRETI, Oreste (Org.). Educação a distância: inícios e indícios de um percurso. Cuiabá: NEAD/IE - UFMT, 1996, pp. 15-56.

SANTOS, Robson, OLIVEIRA, Suzana. Paradigmas educacionais e suas influências na formação e na prática pedagógica de professores. Revista Interface, Goiás, v.00, n. 10, pp. 251-261, dez. 2015. Disponível em: $<$ https://sistemas.uft.edu.br/periodicos/index.php/interface/article/view/1962/8617>. Acesso em: 26 mai. 2018.

TARDIF, Maurice. Saberes profissionais dos professores e conhecimentos universitários: elementos para uma epistemologia da prática profissional dos professores e suas consequências em relação à formação para o magistério. Revista Brasileira de Educação, São Paulo, n. 13, pp. 05-24, jan./abr. 2000. Disponível em: <http://www.joinville.udesc.br/portal/professores/jurema/materiais/ RBDE13_05_MAURICE_TARDIF.pdf>. Acesso em: 20 ago. 2018. 
TORRES, Patrícia Lupion; IRALA, Esrom Adriano Freitas. Aprendizagem colaborativa: teoria e prática. In: TORRES, Patrícia Lupion. (Org.). Complexidade: Redes e Conexões na Produção do Conhecimento. 1. ed. Curitiba: SENARPR, 2014, pp. 61-93.

TORRES, Patrícia Lupion; MARRIOTT, Rita de Cassia Veiga. A aprendizagem colaborativa no LOLA. In: SANTOS, Edmea; ALVES, Lynn (Orgs.). Práticas pedagógicas e tecnologias digitais. Rio de Janeiro: E-papers, 2006, pp. 161-181.

YIN, Robert K. Estudo de caso: planejamento e métodos. Tradução de Ana Thorell. 4.ed. Porto Alegre: Bookman, 2010.

\section{APÊNDICE - INSTRUMENTO DE COLETA DE DADOS}

Prezado (a) aluno (a),

Este questionário de pesquisa tem como objetivo analisar como os princípios do pensamento complexo se fazem presentes nos cursos de formação permanente ofertados pelo Programa Agrinho, na modalidade de EAD, a professores tanto da rede pública como privada. Portanto, é essencial que você responda às questões abaixo com sinceridade.

1) Como você avaliou a sua aprendizagem com esta proposta de Aprendizagem Colaborativa?

2) Para você, quais são as vantagens do uso dos Mapas Conceituais?

3) Quais os seus ganhos, no que diz respeito a apreensão e construção do conhecimento com esta proposta de Aprendizagem Colaborativa?

4) Você acredita que houve uma melhora em seu processo ensino-aprendizagem com o uso de Mapas Conceituais? Como você observou isto? 


\section{Agradecimentos}

Agradecemos aos nossos familiares e amigos, que sempre nos fornecem apoio, compreensão e estímulo para aprendermos cada vez mais.

Este é um artigo de acesso aberto distribuído sob os termos da Licença Creative Commons Atribuição Não Comercial-Compartilha Igual (CC BY-NC- 4.0), que permite uso, distribuição e reprodução para fins não comerciais, com a citação dos autores e da fonte original e sob a mesma licença. 